\title{
Knowledge to Policy: making the most of development research
}

Fred Carden. International Development Research Centre, Canada. Sage, 2009

\author{
Reviewed by Swapna Mukhopadhyay
}

Resources, Energy, and Development 6(2): 93-94

Despite its relatively small size within the donor community, the IDRC (International Development Research Centre) of Canada has, over the years, developed a reputation for supporting good quality development research. This has been made possible by the professional quality and commitment of the programme and managerial staff of the organization, as also by what may be called a tradition of organizational introspection. Such a tradition of self-assessment may have been partially spurred by the pressure of demonstrating 'good performance' to the Canadian government, which the IDRC is constitutionally obligated to do. However, this tradition has also been instrumental in generating valuable insights in designing the IDRC's own future agenda. This is a book that chronicles the efforts of the IDRC in an exercise in self assessment in terms of one specific indicator, that is, the impact of development research projects supported by it in influencing 'Policy' in the countries where they were located. Although the exercise was conceived as an input for internal learning, the author of the volume, who is also the Director of the Evaluation Unit at IDRC, believes that 'the results are important beyond the... cases analysed, and beyond IDRC' (p. 197).

To the lay reader interested in development research projects the book provides interesting material on the business of running them. Given the focus of the volume on research-to-policy issues, the analysis presented here is based on a purposively selected sample of 23 projects around the developing world, which were chosen by project personnel of the IDRC from those that were perceived to have had, if not actual, at least the potential for significant policy impact. The list of projects selected include a wide variety of subjects, from projects on ICT4D (information and communication for development), projects on education and health reforms, poverty monitoring, small business development, trade and finance, environmental projects on fisheries, water management and mining, to primarily economic research projects analysing MIMAP (micro impact of macroeconomic policy reforms), and so on. The location of these projects ranged over Asia, Africa, Latin America, and the Middle East. The list includes one relatively small project from India, although Indian stakeholders in research have been elsewhere lauded for putting on board 'fine examples of how policy relevant research can be put to good use (Malone, 2009*). Based on the experience acquired from the heterogeneous set of examples included in the volume, the attempt has been to glean general insights on the contexts and conditionalities, the processes and mechanisms, as well as the

* Until 2008, David Malone had been Canada's High Commissioner in India. He is currently the President of IDRC. Cf. p10, The Hindu. July 8, 2009. 
optimal timing of feeding research outputs into the policy-making process, in order to ensure that 'policy' is better informed by the 'Knowledge' generated by development research.

I have a small problem with the title of the book. 'Knowledge' is a heavily loaded term. Should one equate an amalgam of results from small development research projects with 'Knowledge', unless one can also demonstrate a reasonable degree of immutability to it? Umpteen number of examples come to mind on how time and context-specific such research results may be. One remembers how in the eighties all donor agencies were vying with one another to promote 'income- generating activities' for poor women, in the unqualified hope that the exposure to the world of paid labour and the incomes it generates will make them 'empowered'. It was only years down the line that it transpired that on their own, without supplementary efforts, most of these activities had only generated more work and less leisure for these women without corresponding control over the resources they had generated. A primary reason why many large-scale poverty alleviation programmes of the Indian government, based on the research findings of Poverty Research, have failed to deliver over the years can be traced to the fact that neither the researchers nor the policy planners have been sufficiently clued in to the harsh ground realities of the lives of the Indian poor. Research results from development projects are not immutable. Unless carefully screened and triangulated for policy-relevant use in a proper context, they may in fact create more harm than good.
That 'Policy' is also a loaded term is acknowledged throughout the book. The writer has dwelt on what exactly this term may signify under different contexts. It is important to acknowledge that getting a government official to attend a workshop or seminar on research dissemination may be a necessary first step but is not tantamount to making a dent on 'Policy', nor is getting an official involved in the research process itself easy. Incremental policy changes may be spearheaded at the margin through the combined efforts of development research professionals in tandem with officials at various levels. However, big policy changes can occur only when a whole array of factors get aligned together.

Surprisingly, there is no assessment in the volume of the larger policy regimes and policymaking scenarios in the countries where these projects were situated, nor any discussion on how these factors may have shaped the feasible set of actions and results in the selected set of projects. Unfortunately, these factors are precisely those that would have been very important in delineating the contextual specificities of the individual projects analysed in the book and would also have been essential in understanding the limits to the generalizability of the results. The volume would have been much enriched by including such analysis, and the results would have been truly important even for the audience 'beyond the IDRC'. 